\title{
Risk of empyema in patients with COPD
}

This article was published in the following Dove Press journal: International Journal of COPD

\author{
Hsueh-Yi Lu' \\ Kuang-Ming Liao ${ }^{2}$ \\ 'Department of Industrial Engineering \\ and Management, National Yunlin \\ University of Science and Technology, \\ Yunlin, ${ }^{2}$ Department of Internal \\ Medicine, Chi Mei Medical Center, \\ Chiali, Taiwan
}

Objective: Pneumonia is one of the most common infectious diseases in patients with COPD. The risk of empyema in COPD is controversial, and its incidence has not been reported. The aim of our study was to determine the risk of empyema in COPD patients and to assess its risk factors.

Patients and methods: We used the National Health Insurance Research Database in Taiwan to conduct an observational cohort study. This study analyzed patients who were diagnosed with COPD between January 1, 2003 and December 31, 2009. The earliest date of COPD diagnosis was designated the index date. Patients who were younger than 40 years or had empyema before the index date were excluded.

Results: We analyzed 72,085 COPD patients in our study. The incidence of empyema was higher in the COPD group than in the non-COPD group ( 15.80 vs 4.34 per 10,000 person-years). The adjusted hazard ratio for empyema was $3.25(95 \% \mathrm{CI}=2.73-3.87)$ in patients with COPD compared with patients without COPD. COPD patients with only comorbidity of stroke, cancer, and chronic renal disease had adjusted hazard ratios of 1.88, 4.84, and 3.90, respectively.

Conclusion: The likelihood of developing empyema is higher in patients with COPD than in those without COPD. Some comorbidities, such as stroke, cancer, and chronic renal disease, are associated with an elevated risk for empyema in COPD patients.

Keywords: risk factors, empyema, COPD

\section{Introduction}

COPD is a chronic inflammatory disease characterized by irreversible airway obstruction. ${ }^{1}$ COPD patients are often colonized with bacteria and viruses that result in airway inflammation. A previous study showed that severe COPD decreased the cytokine response to pathogen-associated molecular patterns and proposed that bacterial colonization may attenuate the systemic innate immune response. ${ }^{2}$ One of the most common infections in COPD patients is pneumonia. ${ }^{3}$ Parapneumonic effusions in the pleural spaces represent a complication of pneumonia and are found in $\sim 40 \%$ of bacterial pneumonia cases. ${ }^{4}$ Parapneumonic pleural effusions are divided into uncomplicated parapneumonic effusions, complicated parapneumonic effusions, and empyema. Complicated parapneumonic effusions and empyema result from bacterial infections in the pleural space. Empyema is characterized by pus-like pleural effusions, an offensive odor, and bacterial isolation from the pleural effusion. Dusemund et al used records from a database from Switzerland between 2002 and 2010 to investigate the outcomes of adult patients with community-acquired pneumonia and COPD and found that the most frequent complication was pleural effusion, which was less frequent in COPD patients than in comparison subjects. The frequency of empyema did not differ between COPD patients and comparison subjects. ${ }^{5}$ Chalmers et al conducted a prospective observational study of patients in the UK and found that COPD was
Correspondence: Kuang-Ming Liao Department of Internal Medicine, Chi Mei Medical Center, Chiali, Taiwan Tel +88667263333 Ext 32003 Emailabc8870@yahoo.com.tw
International Journal of COPD 2018:13 317-324

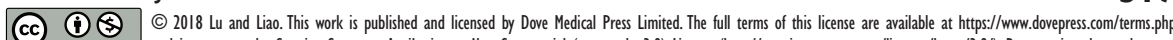
cc. hereby accept the Terms. Non-commercial uses of the work are permitted without any further permission from Dove Medical Press Limited, provided the work is properly attributed. For permission for commercial use of this work, please see paragraphs 4.2 and 5 of our Terms (https://www.dovepress.com/terms.php). 
associated with a decreased risk of developing complicated parapneumonic effusions or empyema. ${ }^{6}$

However, another study ${ }^{7}$ showed that COPD is a risk factor for empyema. Although lung infections such as pneumonia more often occur in COPD patients than in the general population, there is little evidence and much controversy related to the association between COPD and empyema. The purpose of this study was to determine the risk of empyema in COPD patients and to assess the risk factors of empyema in COPD.

\section{Patients and methods}

\section{Ethics statement}

This observational study was evaluated and approved by the Institutional Review Board (IRB) of the Chi Mei Medical Center, Taiwan (IRB: 10601-E01). All personal information from the dataset was de-identified for strict anonymity before further analysis. Informed consent was waived by the approving IRB.

\section{Data sources}

National Health Insurance (NHI) is a public, single-payer insurance program with nationwide coverage in Taiwan that has operated since 1995 . It covers $\sim 99 \%$ of the population and contracts with $97 \%$ of health care providers. The NHI Research Database (NHIRD), authorized and released for research purposes, contains all inpatient and outpatient registration and claim data of the NHI program. The data include patients' demographic characteristics, disease diagnostic, and surgical operation codes (based on the International
Classification of Diseases, Ninth Revision, Clinical Modification [ICD-9-CM]), prescription records, and medical expenditures. The NHIRD is one of the largest administrative health care databases in the world. We retrospectively obtained a longitudinally linked NHIRD subset of 1 million randomly selected enrollees from 1996 to 2010 . Confidential data of the selected subjects were de-identified.

\section{Patients}

This study analyzed patients who were diagnosed with COPD (ICD-9-CM codes 490-492 and 496) between January 1, 2003 and December 31, 2009. To ensure COPD diagnosis, subjects with at least three outpatient visits or one inpatient admission with a main diagnosis of COPD in the NHIRD database were selected. The last date of the three outpatient visits or the first day of the first hospitalization, whichever came earlier, was designated as the index date used to estimate the risk of empyema. Patients who were younger than 40 years, had empyema before the index date, or had incomplete records were excluded. In total, 72,085 qualified patients with COPD were initially retrieved before exclusion filtering (Figure 1). Comparison subjects were selected among hospitalized patients without COPD and were matched according to age in year of the index date $( \pm 3$ years) and sex at a 2:1 ratio.

\section{Empyema and comorbidities}

To investigate the risk of empyema, the patients were followed until the occurrence of empyema (ICD-9-CM code 510), death, withdrawal from the NHI, or the end of 2010.

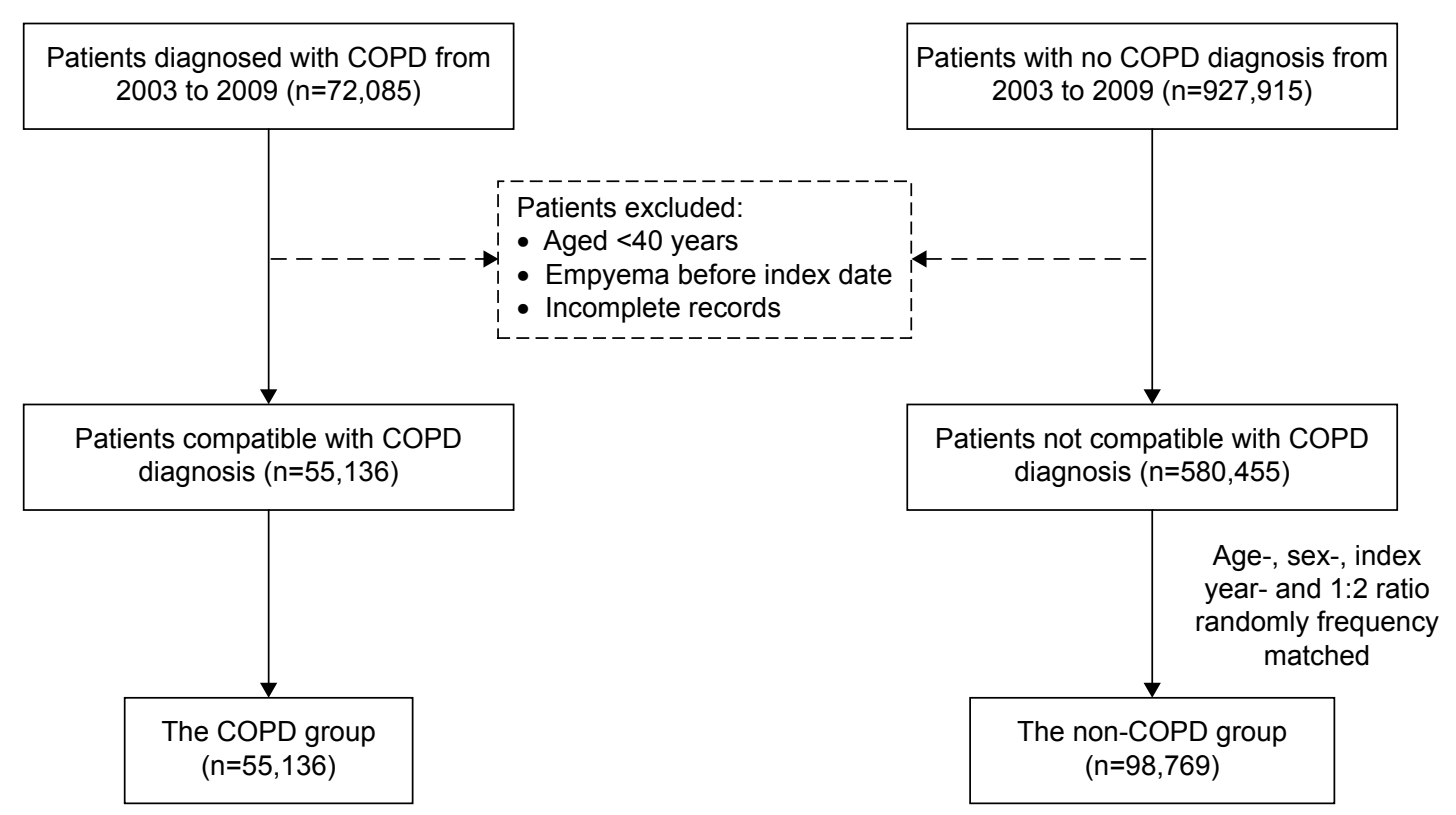

Figure I Flowchart of subject enrollment. 
Comorbidities including diabetes, hypertension, chronic liver disease, stroke, cancer, and chronic renal disease were identified starting from 1 year before the index day according to ICD-9-CM codes in the outpatient and inpatient records.

\section{Statistical analysis}

The demographic variables and comorbidities of the patients with or without COPD are expressed as frequencies (percentages) or mean $( \pm \mathrm{SD})$ and were compared using chi-square tests and Student's $t$-test, respectively. The demographic characteristics included sex and age (stratification into 40-49, 50-59, 60-69, and $>70$ years). Cumulative incidence curves for empyema were plotted using the Kaplan-Meier method, and the differences in curves between patients with and without COPD were analyzed by a log-rank test. The incidence rate of empyema was estimated using the total number of empyema events divided by the total follow-up period (per 10,000 person-years). Cox proportional hazards models were used to measure the main effects of comorbidities among patients on the time to empyema occurrence with adjusted variables, age, and sex, which showed significant association with empyema. Hazard ratios (HRs) and their 95\% CIs were estimated. Variables with significant values in the univariable model were further examined in the Cox regression model. All statistical tests were two-sided, and a $P$-value of 0.05 was considered significant. The statistical analyses were performed using SPSS (version 15; SPSS Inc., Chicago, IL, USA).

\section{Results \\ Patient characteristics}

The study groups included 55,136 patients diagnosed with COPD and 98,769 patients without COPD (Figure 1). In the COPD group, the mean age was $65.4 \pm 13.2$ years, with $41.3 \%$ of the patients aged $\geq 70$ years, and $56.6 \%$ of the patients were male (Table 1). Likewise, in the non-COPD group, the mean age was $65.7 \pm 11.7$ years, with $38.7 \%$ aged $\geq 70$ years, and $53.2 \%$ were male. The distributions of age and sex were similar between both groups.

Patients in the COPD group had a higher prevalence of comorbidities than those in the non-COPD group (diabetes [ $17.8 \%$ vs $14.8 \%$ ], hypertension [ $43.9 \%$ vs $33.4 \%$ ], chronic liver disease $[10.7 \%$ vs $6.7 \%$, stroke [13.6\% vs $8.0 \%$, cancer $[1.4 \%$ vs $0.9 \%$, and chronic renal disease $[1.7 \%$ vs $1.2 \%])$.

\section{Incidence of empyema}

As shown in Table 2, the overall incidence rate of empyema was higher in the COPD group than in the non-COPD group
Table I Demographic characteristics and comorbidities of patients with and without COPD

\begin{tabular}{|c|c|c|c|}
\hline Variables & $\begin{array}{l}\text { With } \\
\text { COPD } \\
(n=55,136)\end{array}$ & $\begin{array}{l}\text { Without } \\
\text { COPD } \\
(n=98,769)\end{array}$ & $P$-value \\
\hline \multicolumn{4}{|l|}{ Age, years } \\
\hline $40-49$ & $8,764(15.9)$ & II,437 (I I.6) & - \\
\hline $50-59$ & I I,039 (20.0) & $21,323(21.6)$ & \\
\hline $60-69$ & $|2,54|(22.7)$ & $27,8 \mid 8(28.2)$ & \\
\hline$\geq 70$ & $22,792(4 \mid .3)$ & 38,191 (38.7) & \\
\hline Mean $( \pm S D)$ & $65.4(13.2)$ & $65.7(11.7)$ & - \\
\hline \multicolumn{4}{|l|}{ Sex } \\
\hline Male & $31,185(56.6)$ & $52,539(53.2)$ & - \\
\hline Female & $23,95 I(43.4)$ & $46,230(46.8)$ & \\
\hline \multicolumn{4}{|l|}{ Comorbidities } \\
\hline Diabetes & $9,803(17.8)$ & $14,650(14.8)$ & $<0.001$ \\
\hline Hypertension & $24,189(43.9)$ & $33,002(33.4)$ & $<0.001$ \\
\hline Chronic liver disease & $5,909(10.7)$ & $6,630(6.7)$ & $<0.001$ \\
\hline Stroke & 7,509 (I3.6) & $7,865(8.0)$ & $<0.001$ \\
\hline Cancer & $751(1.4)$ & $890(0.9)$ & $<0.001$ \\
\hline Chronic renal disease & $958(1.7)$ & $\mathrm{I}, \mathrm{I} 52(\mathrm{I} .2)$ & $<0.001$ \\
\hline
\end{tabular}

(15.8 vs 4.3 per 10,000 person-years). The adjusted HR (aHR $3.25,95 \% \mathrm{CI}=2.73-3.87$ ) of empyema indicated that the risk of empyema was 3.25 times higher for COPD patients than for non-COPD patients.

This relationship was further investigated by examining the associations between age, sex, and comorbidities. In the COPD group, the age-stratified incidence rates of empyema increased with age $(7.44,10.33,13.26$, and 24.15 for subjects aged $40-49,50-59,60-69$, and $>70$ years, respectively). Similarly, increased incidence rates with age were also found in the non-COPD group. Cox regression showed that age, sex, and comorbidities were associated with higher risks of empyema in the COPD group than in the non-COPD group (Table 2). For example, among patients with diabetes, the aHR of empyema in the COPD group was 2.48 times ( $95 \% \mathrm{CI}=1.73-3.55 ; P<0.001)$ higher than in the non-COPD group.

\section{Comorbidities and empyema occurrence}

We further investigated the associations between comorbidities and empyema occurrence among COPD patients (Table 3). The baseline group $(n=20,285)$ included COPD patients with no comorbidities for comparisons with patients with one comorbidity. COPD patients with only comorbid diabetes had a marginally increased risk of empyema (aHR $1.65,95 \% \mathrm{CI}=0.98-2.78 ; P=0.06$ ). Similarly, significantly increased risks of empyema were found with only stroke (aHR $1.88,95 \% \mathrm{CI}=1.13-3.11 ; P=0.02$ ), only cancer (aHR 4.84 , $95 \% \mathrm{CI}=1.97-11.8 ; P<0.001)$, and only chronic renal disease (aHR 3.90, 95\% CI $=1.24-12.3 ; P<0.02$ ). The significant 
Table 2 Incidence of empyema in patients with and without COPD

\begin{tabular}{|c|c|c|c|c|c|c|c|c|}
\hline \multirow[t]{2}{*}{ Characteristics } & \multicolumn{3}{|c|}{ COPD $(55,136)$} & \multicolumn{3}{|c|}{ Non-COPD $(98,769)$} & \multirow[t]{2}{*}{$\operatorname{aHR}(95 \% \mathrm{Cl})$} & \multirow[t]{2}{*}{$P$-value } \\
\hline & Event & TFP (PY) & IR & Event & TFP (PY) & IR & & \\
\hline Empyema & 386 & $244,362.87$ & 15.80 & 200 & $461,321.38$ & 4.34 & $3.25(2.73-3.87)$ & $<0.001$ \\
\hline \multicolumn{9}{|l|}{ Age } \\
\hline $40-49$ & 31 & $41,680.56$ & 7.44 & 13 & $55,390.38$ & 2.35 & $3.15(1.65-6.02)$ & 0.001 \\
\hline $50-59$ & 52 & $50,346.59$ & 10.33 & 30 & $101,054.57$ & 2.97 & $3.44(2.20-5.40)$ & $<0.001$ \\
\hline $60-69$ & 79 & $59,593.92$ & 13.26 & 61 & $142,218.16$ & 4.29 & $3.08(2.2|-4.3|)$ & $<0.001$ \\
\hline 70 and above & 224 & $92,741.79$ & 24.15 & 96 & $162,658.27$ & 5.90 & $4.03(3.17-5.11)$ & $<0.001$ \\
\hline \multicolumn{9}{|l|}{ Sex } \\
\hline Male & 307 & $|36,358.6|$ & 22.51 & 141 & $241,609.18$ & 5.84 & $3.82(3.13-4.66)$ & $<0.001$ \\
\hline Female & 79 & $108,004.26$ & 7.314 & 59 & $219,712.20$ & 2.69 & $2.72(1.94-3.82)$ & $<0.001$ \\
\hline \multicolumn{9}{|l|}{ Comorbidities } \\
\hline \multicolumn{9}{|l|}{ Diabetes } \\
\hline Yes & 77 & $40,652.56$ & 18.94 & 49 & $64,748.28$ & 7.57 & $2.48(1.73-3.55)$ & $<0.001$ \\
\hline No & 309 & $203,710.31$ & 15.17 & $15 \mid$ & $396,573.10$ & 3.81 & $3.95(3.25-4.80)$ & $<0.001$ \\
\hline \multicolumn{9}{|l|}{ Hypertension } \\
\hline Yes & 176 & $105,678.82$ & 16.65 & 87 & $148,456.57$ & 5.86 & $2.82(2.18-3.64)$ & $<0.001$ \\
\hline No & 210 & $138,684.05$ & 15.14 & 113 & $3|2,864.8|$ & 3.61 & $4.16(3.31-5.23)$ & $<0.001$ \\
\hline \multicolumn{9}{|c|}{ Chronic liver disease } \\
\hline Yes & 39 & $27,053.66$ & 14.42 & 26 & $31,388.63$ & 8.28 & $1.73(1.06-2.85)$ & 0.03 \\
\hline No & 347 & $217,309.21$ & 15.97 & 174 & $429,932.75$ & 4.05 & 3.91 (3.26-4.69) & $<0.001$ \\
\hline \multicolumn{9}{|l|}{ Stroke } \\
\hline Yes & 92 & $29,672.67$ & 31.00 & 25 & $34,088.21$ & 7.33 & $4.14(2.66-6.45)$ & $<0.001$ \\
\hline No & 294 & $214,690.20$ & 13.69 & 175 & $427,233.18$ & 4.10 & $3.32(2.76-4.01)$ & $<0.001$ \\
\hline \multicolumn{9}{|l|}{ Cancer } \\
\hline Yes & 10 & I,91।.98 & 52.30 & 3 & $3,118.55$ & 9.62 & $4.52(1.24-16.46)$ & 0.022 \\
\hline No & 376 & $242,450.88$ & $|5.5|$ & 197 & $458,202.84$ & 4.30 & $3.58(3.01-4.26)$ & $<0.001$ \\
\hline \multicolumn{9}{|c|}{ Chronic renal disease } \\
\hline Yes & 11 & $3,248.93$ & 33.86 & 3 & $4,084.66$ & 7.34 & 4.59 (1.28-16.47) & 0.019 \\
\hline No & 375 & $24 I, I 13.94$ & 15.55 & 197 & $457,236.72$ & 4.31 & $3.58(3.01-4.26)$ & $<0.001$ \\
\hline
\end{tabular}

Abbreviations: aHR, adjusted hazard ratio; IR, incident rate per 10,000 person-years; PY, per 10,000 person-years; TFP, total follow-up period.

values of the aHR increased (from 1.25 to 1.54) when the number of comorbidities increased (from $\geq 1$ to $\geq 3$ ).

\section{Cumulative incidence rates of empyema} Cumulative incidence curves for the COPD and non-COPD groups used to estimate the occurrence of empyema over time (Figure 2) showed significant differences between the two study groups $(P<0.05$, log-rank test). As shown in Figure 3, COPD patients with only comorbid diabetes showed a significantly higher risk of empyema than COPD patients with no comorbidities and non-COPD patients with only comorbid diabetes $(P<0.05$, log-rank test). Similar patterns of empyema risk were also found for COPD patients with only stroke (Figure 4 ) or only cancer (Figure 5 ).

Table 3 Impact of comorbidities on empyema among COPD patients $(n=55,136)$

\begin{tabular}{lllll}
\hline Comorbidity & Number (\%) & Event & aHR (95\% CI) & P-value \\
\hline No comorbidity & $20,285(36.8)$ & 126 & - & - \\
Diabetes only & $1,596(2.9)$ & 16 & $1.65(0.98-2.78)$ & 0.06 \\
Hypertension only & $10,27 I(18.6)$ & 68 & $1.05(0.78-1.42)$ & 0.73 \\
Chronic liver disease only & $1,788(3.2)$ & 14 & $1.24(0.72-2.16)$ & 0.44 \\
Stroke only & $1,612(2.9)$ & 17 & $1.88(1.13-3.11)$ & 0.02 \\
Cancer only & $271(0.5)$ & 5 & $3.84(1.97-11.8)$ & 0.001 \\
Chronic renal disease only & $153(0.3)$ & 3 & $3.90(1.24-12.3)$ & 0.02 \\
$\geq 1$ comorbidity & $34,851(63.2)$ & 260 & $1.25(1.01-1.55)$ & 0.04 \\
$\geq 2$ comorbidities & $17,152(31.1)$ & 129 & $1.29(1.01-1.65)$ & 0.04 \\
$\geq 3$ comorbidities & $6,057(I I .0)$ & 53 & $1.54(1.11-2.12)$ & 0.01 \\
\hline
\end{tabular}

Abbreviation: aHR, adjusted hazard ratio. 


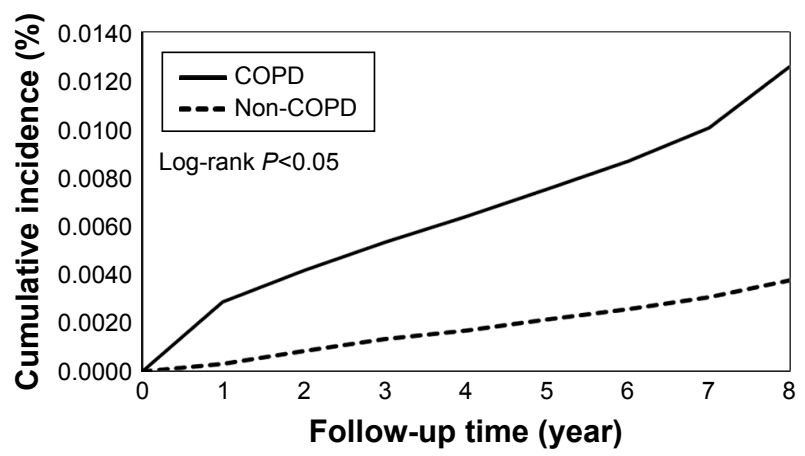

Figure 2 Cumulative incidence of empyema in patients with and without COPD.

\section{Discussion}

In our study, the percentages of comorbidities, including diabetes, hypertension, hyperlipidemia, chronic liver disease, stroke, cancer, chronic renal disease, and autoimmune disease, were much higher in COPD patients than in patients without COPD. The incidence of empyema was higher in COPD patients, with an aHR of 3.25, and age was associated with an increased risk of empyema. The two comorbidities associated with the greatest increase in risk for empyema in COPD patients compared to non-COPD patients were chronic renal disease and cancer, with aHR values of 4.56 and 4.52, respectively. Among the COPD group of patients, an increased number of comorbidities increased the risk of empyema, and the two most serious comorbidities were cancer and chronic renal disease.

\section{Diabetes and empyema}

Diabetes is associated with abnormal microvascular and neurologic parameters and a risk of infection. ${ }^{8}$ Infections are frequently observed in the respiratory system due to inadequate clearance or the disturbance of normal pulmonary immune function. ${ }^{9}$ Diabetes is an independent risk factor for

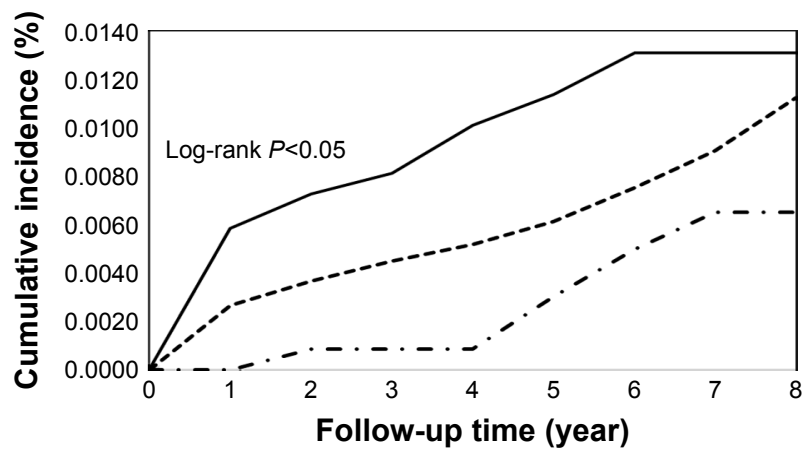

$$
\text { - COPD only diabetes --- COPD no comorbidity }
$$$$
\text { - . Without COPD only diabetes }
$$

Figure 3 Cumulative incidence of empyema in patients with only diabetes.

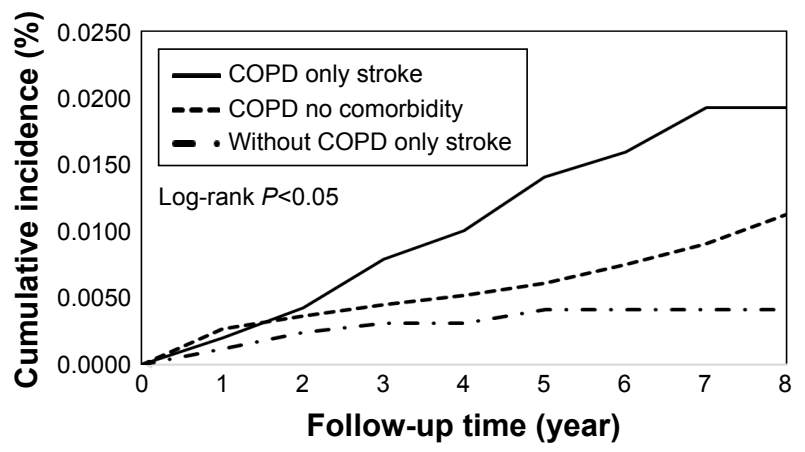

Figure 4 Cumulative incidence of empyema in patients with only stroke.

airway infection, including pneumonia. In addition, patients with both diabetes and pneumonia have an increased risk of complications, such as bacteremia or recurrent pneumonia, and increased mortality rates have been observed in these patients. ${ }^{10,11}$ A previous study also showed that diabetes is the most common underlying condition in acute thoracic empyema. ${ }^{12}$ Our study showed that patients with COPD and diabetes, regardless of other comorbidities, have an increased risk of empyema, with an aHR of 2.82. Previous studies have shown that diabetic patients are predisposed to pleural involvement in cases of fungal or aerobic Gram-negative bacterial infections. ${ }^{13-15}$ As our database lacks laboratory data, we cannot further analyze bacteriology data in patients with empyema.

\section{Stroke and empyema}

Stroke patients have an increased risk of complications, and the frequency and type of complications are associated with the severity of neurologic and functional deficits. These complications result in prolonged hospitalization, poor quality of life, and increased mortality. ${ }^{16}$ One common complication after stroke is aspiration, but the frequency of aspiration may

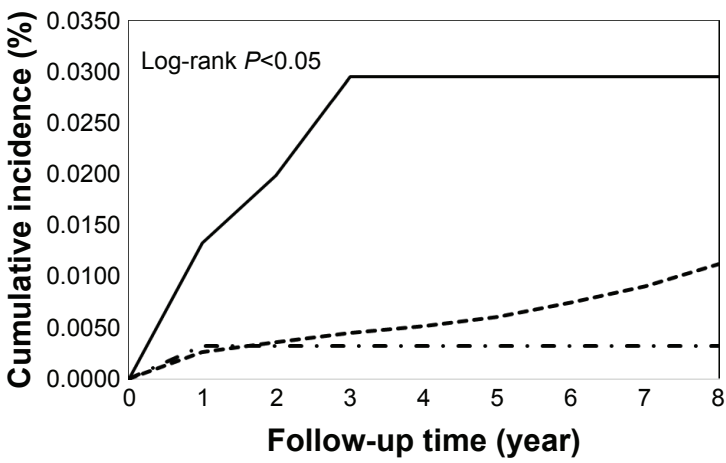

— COPD only cancer -.- COPD no comorbidity - . Without COPD only cancer

Figure 5 Cumulative incidence of empyema in patients with only cancer. 
be underreported or underdiagnosed. Pneumonia is a frequent sequela of aspiration in stroke patients ${ }^{17}$ and is associated with higher mortality. ${ }^{18}$ Some stroke patients with pneumonia may progress to empyema, and a delayed diagnosis without prompt treatment due to neurologic deficits can result in a poor prognosis. Few studies have investigated the association between stroke and empyema. Monteiro et a ${ }^{19}$ conducted an observational study of medical records for lung abscesses or empyema between 2000 and 2008 and found that the most frequent disorder among these patients was stroke-associated disability (46.7\%).

Shen at $\mathrm{al}^{20}$ used the NHIRD to examine the risk of developing empyema in patients with stroke and showed that the incidence of empyema was higher in patients with stroke than in patients without stroke, with an aHR of 2.89 (95\% CI $=2.72-3.08)$.

They further subdivided the patients with stroke into ischemic and hemorrhagic stroke groups and found that the aHRs of empyema were $2.62(95 \% \mathrm{CI}=2.45-2.79)$ for ischemic stroke and 4.53 (95\% CI =4.14-4.95) for hemorrhagic stroke, compared with patients without stroke. Stroke patients with ventriculoperitoneal shunt implantation were seven times more likely to develop empyema. In our study, patients with both COPD and stroke had an increased risk of empyema, with an aHR of 4.14, compared with COPD patients without stroke. Stroke is a risk factor of empyema not only in the general population but also in COPD patients. Prompt detection of empyema in stroke patients who are unable to communicate is the most crucial aspect of clinical management.

\section{Cancer and empyema}

Empyema in patients with a cancer history may be due to immunosuppression, disease complications of cancer, and the influence of pneumonia or necrotic tissue after chemotherapy or invasive procedures. ${ }^{21}$ The incidence of empyema in patients with primary lung cancer is low, ranging from $0.1 \%$ to $0.3 \% .^{22}$ The differentiation between empyema and cancer is not always clear, and managing empyema in patients with cancer remains challenging. The cause of empyema, whether it is a consequence of lung infection or associated with cancer and lung metastasis, will lead to different clinical management strategies and prognoses. The study of empyema, including differential counts of white blood cells, gram staining, cultures, and cytological examinations, is necessary. A bidirectional relationship exists between cancer and empyema. Patients with cancer had an increased risk of empyema in both the COPD and non-COPD groups. An increased risk of cancer has been reported in patients with inflammatory and infectious diseases. ${ }^{23,24}$ Previous studies have shown that empyema is associated with an increased incidence of cancer among individuals older than 60 years, male, and patients with comorbidities such as diabetes and liver cirrhosis, compared to the general population. ${ }^{25}$ Only 13 patients had cancer in our study. Further studies are needed to determine the impact of different types of cancer on the development of empyema.

\section{Chronic renal disease and empyema}

Chronic renal disease and end-stage renal disease are associated with disturbances of host defenses and susceptibility to infection due to older age, immune dysfunction, comorbidities, and dialysis. ${ }^{26}$ Patients with renal impairment are associated with an increased risk of pneumonia. ${ }^{27,28}$ Chen et al conducted a retrospective study from January 2001 to March 2006 at a medical center to elucidate the clinical features, pathogens, and outcomes among patients with both empyema and chronic renal disease or end-stage renal disease. ${ }^{29}$ They found that $77.6 \%$ of empyema cases were secondary to pneumonia. Klebsiella pneumoniae (34\%) was the predominant pathogen in patients before they received hemodialysis, and aerobic Gram-positive organisms were the main pathogens in patients after they received hemodialysis. Previous data have shown that the impaired immune function associated with uremia is related to serum factors and altered membrane functions in cell lines. Uremic concentrations of guanidino compounds can inhibit neutrophil superoxide formation, which has implications for neutrophil function in host defense. ${ }^{30}$ Shen et al conducted a retrospective cohort study using data from the NHIRD of Taiwan. Their data showed that the incidence of empyema in patients with end-stage renal disease was 2.76-fold higher than in patients without end-stage renal disease (23.7 vs $8.19 / 10,000$ person-years; $P<0.001)$, with an aHR of $3.01(95 \% \mathrm{CI}=2.67-3.39)$, but no difference was observed in the risk of empyema between hemodialysis and peritoneal dialysis. ${ }^{31}$ Our data showed that patients with COPD and chronic renal disease (including before and after receiving hemodialysis) had the highest risk of empyema compared with those with other comorbidities, with an aHR of 4.56. Physicians may need to pay closer attention to patients with COPD and chronic renal disease who have pneumonia due to the high risk of empyema.

\section{Limitations}

There are some limitations in our study that should be considered when interpreting the data. First, we used the ICD-9-CM to define patients with COPD, empyema, and other comorbidities. Over- or underdiagnosis could be argued. 
However, the accuracy of claims data has been evaluated and validated..$^{32}$ Second, the claims data did not include smoking status, pulmonary function tests, alcohol consumption, socioeconomic status, performance status, the severity of empyema, relevant clinical information on laboratory data, or imaging data. Third, the case numbers were small in the cancer, chronic renal disease, and autoimmune disease groups. We may need larger populations to verify the association between comorbidities and empyema.

\section{Conclusion}

The incidence of developing empyema is higher in COPD patients than in patients without COPD. Some comorbidities, such as stroke, cancer, and chronic renal disease, are associated with an elevated risk of empyema in COPD patients. Patients with COPD and comorbidities may require more attention because they have a high risk of developing empyema.

\section{Acknowledgments}

The authors express their sincere gratitude to Mr Zhe-Wei $\mathrm{Xu}$ (Department of Industrial Engineering and Management, National Yunlin University of Science and Technology) for his effort in organizing data and assisting statistical analysis.

\section{Disclosure}

The authors report no conflicts of interest in this work.

\section{References}

1. Global Initiative for Chronic Obstructive Lung Disease (GOLD): global strategy for the diagnosis, management and prevention of chronic obstructive pulmonary disease; NHLBI/WHO workshop report; NIH Publication No 2701A. Last update 2015. Available from: http://www. goldcopd.com. Accessed August 23, 2017.

2. Fan VS, Gharib SA, Martin TR, Wurfel MM. COPD disease severity and innate immune response to pathogen-associated molecular patterns. Int J Chron Obstruct Pulmon Dis. 2016;11:467-477.

3. Liao KM, Lin TC, Li CY, Yang YH. Dementia increases severe sepsis and mortality in hospitalized patients with chronic obstructive pulmonary disease. Medicine (Baltimore). 2015;94(23):e967.

4. Light RW, Girard WM, Jenkinson SG, George RB. Parapneumonic effusions. Am J Med. 1980;69(4):507-512.

5. Dusemund F, Chronis J, Baty F, Albrich WC, Brutsche MH. The outcome of community-acquired pneumonia in patients with chronic lung disease. Swiss Med Wkly. 2014;144:w14013.

6. Chalmers JD, Singanayagam A, Murray MP, Scally C, Fawzi A, Hill AT. Risk factors for complicated parapneumonic effusion and empyema on presentation to hospital with community-acquired pneumonia. Thorax. 2009;64(7):592-597.

7. Ferguson AD, Prescott RJ, Selkon JB, Watson D, Swinburn CR. The clinical course and management of thoracic empyema. QJM. 1996; 89(4):285-289.

8. Koziel H, Koziel MJ. Pulmonary complications of diabetes mellitus. Pneumonia. Infect Dis Clin North Am. 1995;9(1):65-96.

9. Marvisi M, Bartolini L, del Borrello P, et al. Pulmonary function in noninsulin-dependent diabetes mellitus. Respiration. 2001;68(3):268-272.
10. Boyko EJ, Lipsky BA, Sandoval R, et al. NIDDM and prevalence of nasal Staphylococcus aureus colonization. San Luis Valley Diabetes Study. Diabetes Care. 1989;12(3):189-192.

11. Casqueiro J, Casqueiro J, Alves C. Infections in patients with diabetes mellitus: a review of pathogenesis. Indian J Endocrinol Metab. 2012; 16(Suppl 1):S27-S36.

12. Chen KY, Hsueh PR, Liaw YS, Yang PC, Luh KT. A 10-year experience with bacteriology of acute thoracic empyema: emphasis on Klebsiella pneumoniae in patients with diabetes mellitus. Chest. 2000;117(6): $1685-1689$.

13. Varkey B, Rose HD, Kutty CP, Politis J. Empyema thoracis during a ten-year period: analysis of 72 cases and comparison to a previous study (1952-1967). Arch Intern Med. 1981;141(13):1771-1776.

14. Mayo P. Early thoracotomy and decortication for nontuberculous empyema in adults with and without underlying diseases: a 25 -year review. Am Surg. 1985;51(4):230-236.

15. Smith JA, Mullerworth MH, Westlake GW, Tatoulis J. Empyema thoracis: a 14-year experience in a teaching center. Ann Thorac Surg. 1991; 51(1):39-42.

16. Kalra L, Yu G, Wilson K, Roots P. Medical complications during stroke rehabilitation. Stroke. 1995;26(6):990-994.

17. Dobkin B. Neuromedical complications in stroke patients transferred for rehabilitation before and after diagnostic related groups. $J$ Neurol Rehabil. 1987;1(1):3-7.

18. Koennecke HC, Belz W, Berfelde D, et al; Berlin Stroke Register Investigators. Factors influencing in-hospital mortality and morbidity in patients treated on a stroke unit. Neurology. 2011;77(10):965-972.

19. Monteiro R, Alfaro TM, Correia L, Simão A, Carvalho A, Costa JN Lung abscess and thoracic empyema: retrospective analysis in an internal medicine department. Acta Med Port. 2011;24(Suppl 2): $229-240$.

20. Shen TC, Lin CY, Lin CL, et al. Risk of developing pleural empyema in patients with stroke: a propensity-matched cohort study. Intern Emerg Med. 2017;12(8):1131-1138.

21. Gonzalez Barcalaa FJ, Temesa E, Moldes M, Pena A, Valdes L. Bronchogenic carcinoma presenting as pleural empyema. Respir Med Ext. 2006;2(4):139-140.

22. Koike T, Takizawa T, Akamatsu H, Yuuzou K, Yokoyama A, Honma T. [Resection of lung cancer complicated by pleural empyema]. Nihon Kyobu Shikkan Gakkai Zasshi. 1995;33(6):670-673. Japanese.

23. Grivennikov SI, Greten FR, Karin M. Immunity, inflammation, and cancer. Cell. 2010;140(6):883-899.

24. Lee PC, Hu YW, Hung MH, et al. The risk of cancer in patients with benign anal lesions: a nationwide population-based study. Am J Med. 2013;126(12):1143.e9-e18.

25. Teng CJ, Hu YW, Yeh CM, Chen TJ, Liu CJ. Cancer risk in patients with empyema: a nationwide population-based study. Medicine (Baltimore). 2016;95(9):e2934.

26. Pesanti EL. Immunologic defects and vaccination in patients with chronic renal failure. Infect Dis Clin North Am. 2001;15(3):813-832.

27. Sarnak MJ, Jaber BL. Pulmonary infectious mortality among patients with end-stage renal disease. Chest. 2001;120(6):1883-1887.

28. Berman SJ, Johnson EW, Nakatsu C, Alkan M, Chen R, LeDuc J. Burden of infection in patients with end-stage renal disease requiring long-term dialysis. Clin Infect Dis. 2004;39(12):1747-1753.

29. Chen $\mathrm{CH}, \mathrm{Hsu} \mathrm{WH}, \mathrm{Chen} \mathrm{HJ}$, et al. Different bacteriology and prognosis of thoracic empyemas between patients with chronic and end-stage renal disease. Chest. 2007;132(2):532-539.

30. Hirayama A, Noronha-Dutra AA, Gordge MP, Neild GH, Hothersall JS Uremic concentrations of guanidino compounds inhibit neutrophil superoxide production. Kidney Int Suppl. 2001;78:S89-S92.

31. Shen TC, Chen CH, Wang IK, et al. Risk of empyema in patients with end-stage renal disease: a nationwide propensity-matched cohort study. QJM. 2017;110(7):425-430.

32. Hsieh CY, Chen CH, Li CY, Lai ML. Validating the diagnosis of acute ischemic stroke in a National Health Insurance claims database. J Formos Med Assoc. 2015;114(3):254-259. 


\section{Publish your work in this journal}

The International Journal of COPD is an international, peer-reviewed This journal is indexed on PubMed Central, MedLine and CAS. The journal of therapeutics and pharmacology focusing on concise rapid reporting of clinical studies and reviews in COPD. Special focus is given to the pathophysiological processes underlying the disease, intervention programs, patient focused education, and self management protocols. manuscript management system is completely online and includes a very quick and fair peer-review system, which is all easy to use. Visit http://www.dovepress.com/testimonials.php to read real quotes from published authors.

Submit your manuscript here: http://www.dovepress.com/international-journal-of-chronic-obstructive-pulmonary-disease-journal 